\title{
Gallstone Ileus-A Case Report with Review of the Literature
}

\author{
Christos Konstantinidis*, Aleksandros Hamzin, Ioannis Stefanidis \\ Surgical Department, Hippocratio General Hospital of Athens, Athens 11527, Region of Attica, Greece \\ *Corresponding author: drchriskons@yahoo.gr
}

Received March 06, 2015; Revised March 16, 2015; Accepted April 15, 2015

\begin{abstract}
A 64 years-old female patientreferred to our hospital for further treatmentof gallstone ileusdiagnosed at another hospital. She had a past medical history of thyroidectomy and mild heart failure. After four days of conservative treatment she underwent scheduled laparotomy with enterolithotomy and stone extraction. Although the operation was uneventful, immediately after that in the recovery room the patient presented severe ARDS with pulmonal edema and acute renal failure. The patientdeceased two days later.
\end{abstract}

Keywords: gallstone,ileus, enterolithotomy, cholelithiasis, Rigler's triad, pneumobilia

Cite This Article: Christos Konstantinidis, Aleksandros Hamzin, and Ioannis Stefanidis, "Gallstone Ileus-A Case Report with Review of the Literature.” American Journal of Medical Case Reports, vol. 3, no. 5 (2015): 126-129. doi: 10.12691/ajmcr-3-5-2.

\section{Introduction}

Gallstone ileus (GI) is rarely seen, occurring in $0.3 \%$ $0.5 \%$ of patients with gallstone disease [1,2]. Usually affects elderly patients with a history of chronic cholecystitis, due to cholecystolithiasis. The result of chronic irritation, inflammation and pressure is the formation of a fistula, usually cholecystoduodenal. Through this communication gallstones can pass into the gastrointestinal tract. As stones migrate, depending on their size, they can cause mechanical bowel obstruction, resulting in colicky abdominal pain, distension, constipation and vomiting. For patients not properly treated, dehydration with electrolyte disturbances and deterioration of general medical condition results.

\section{Case Report}

A 64 years-old female patient with a medical history of thyroidectomy and mild heart failure, referred to the emergency department of our hospital with gallstone ileus, diagnosed at another hospital the same day. She presented there with symptoms of obstructive ileus started few days prior. Initial plain abdominal radiography showed pneumobilia (Figure 1). Suspected gallstone ileus was confirmed with abdominal CT (Figure 2), showing a gallstone impacted into the duodenum, a distended stomach and no imagination of the gallbladder. The patient was admitted to us for further treatment. On physical examination the abdomen was not distended or painful. Blood tests revealed normal white blood cells count and renal function but impaired liver test values (Table 1). The stomach was decompressed via nasogastric tube and a conservative treatment with rehydration was started. The patient underwent MRI of the abdomen, with some additional CT views, which revealed migration of the gallstone to the jejunum, obstructing it (Figure 3). On fourth day of patient's referral to our hospital, she underwent laparotomy, which confirmed the imaging finding.

Table 1. Laboratory Data on Admission

\begin{tabular}{|c|c|c|c|c|c|}
\hline \multicolumn{5}{|c|}{ Complete blood cell count ChemistryCoagulation } \\
\hline WBCs: & $8,06 \times 10^{3} / \mathrm{Ul}$ & Glucose: & $97 \mathrm{mg} / \mathrm{dL}$ & PT (sec): & 11.4 \\
\hline RBCs: & $4,97 \times 10^{3} / \mathrm{uL}$ & BUN: & $42 \mathrm{mg} / \mathrm{dL}$ & aPTT (sec): & 27.1 \\
\hline Hemoglobin: & $14.9 \mathrm{~g} / \mathrm{dL}$ & Creatinine: & $0.8 \mathrm{mg} / \mathrm{dL}$ & INR: & 1 \\
\hline Hematocrit: & $45 \%$ & K: & $4.3 \mathrm{meq} / \mathrm{L}$ & & \\
\hline MCV: & $90.5 \mathrm{fL}$ & Na: & $135 \mathrm{meq} / \mathrm{L}$ & \multicolumn{2}{|c|}{ Immunology } \\
\hline MCH: & $29.9 \mathrm{pg}$ & SGOT: & $192 \mathrm{IU} / \mathrm{L}$ & \multicolumn{2}{c|}{} \\
\hline MCHC: & $33 \mathrm{~g} / \mathrm{dL}$ & SGPT: & $927 \mathrm{IU} / \mathrm{L}$ & AFP: & $1.67 \mathrm{ng} / \mathrm{ml}$ \\
\hline Platelets: & $141 \times 10^{3} / \mathrm{uL}$ & ALP: & $232 \mathrm{IU} / \mathrm{L}$ & CEA: & $1.29 \mathrm{ng} / \mathrm{ml}$ \\
\hline Neutrophils & $86.7 \%$ & $\gamma$-GTP: & $197 \mathrm{IU} / \mathrm{L}$ & Ca19-9: & $16.59 \mathrm{U} / \mathrm{ml}$ \\
\hline Lymphocytes & $5.1 \%$ & Amylase: & $29 \mathrm{IU} / \mathrm{L}$ & & \\
\hline Monocytes & $5.2 \%$ & T-BIL: & $2.2 \mathrm{mg} / \mathrm{dL}$ & & \\
\hline Eosinophils & $1 \%$ & D-BIL: & $1.18 \mathrm{mg} / \mathrm{dL}$ & & \\
\hline Basophils & $0.5 \%$ & LDH & $273 \mathrm{IU} / \mathrm{L}$ & & \\
\hline
\end{tabular}




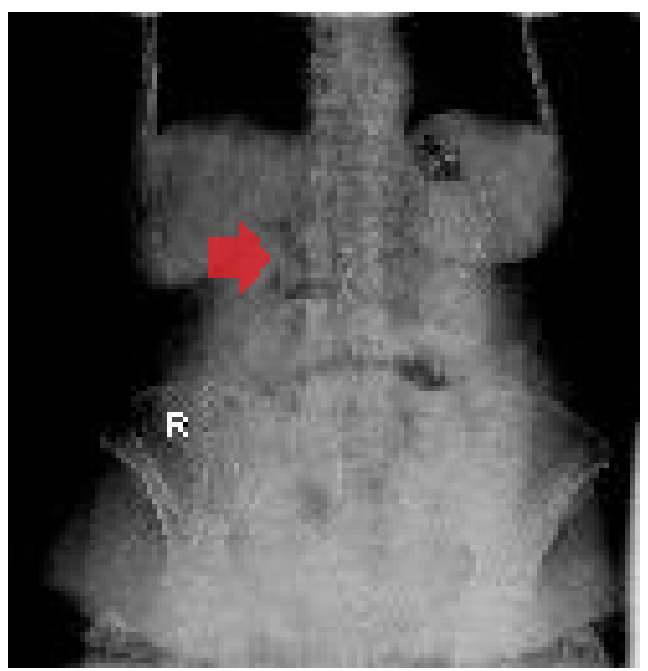

Figure 1. Plain abdominal radiography showing pneumobilia (red arrow)

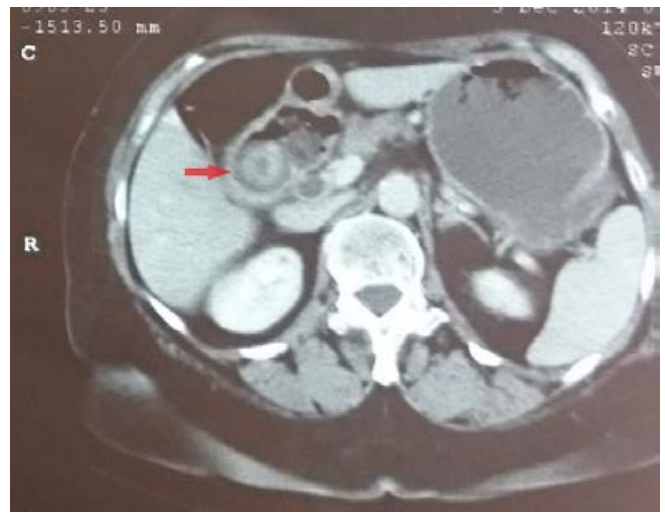

Figure 2. Abdominal CT scan showing a gallstone impacted into the duodenum, the distended stomach and no imagination of the gallbladder (red arrow)

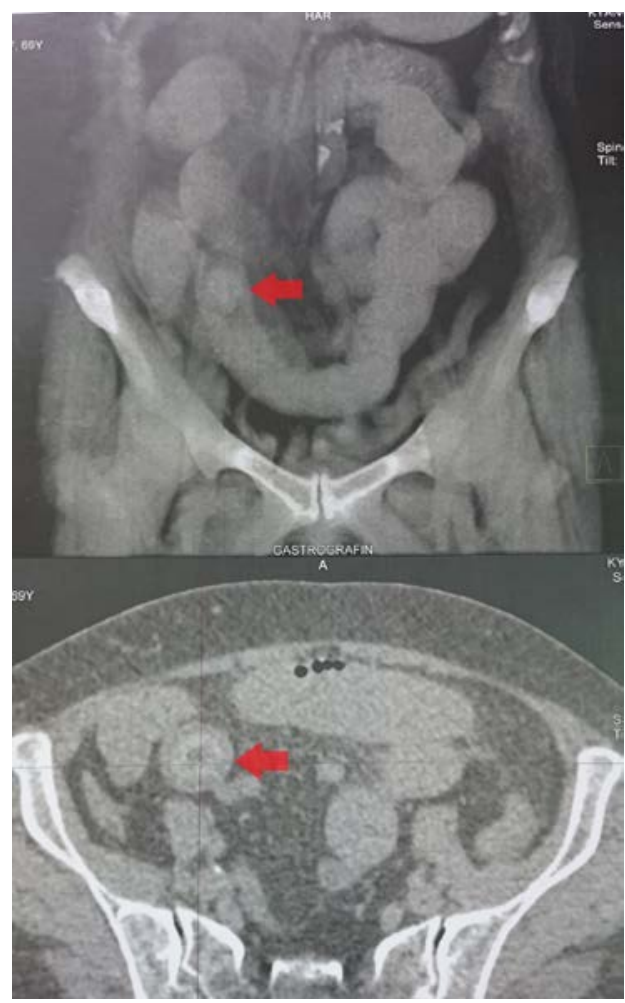

Figure 3. Additional CT scan, showing migration of the gallstone to the jejunum, obstructing it
A gallstone impacted into the intestinum, away from the ileocecal valve (Figure 4). Enterolithotomy on the anti-mesenteric surface of the intestine with stone extraction was undertaken (Figure 5). The stone measured $4 \times 3 \times 3 \mathrm{~cm}$ (Figure 6). A longitudinal enterotomy was performed and the incision sutured transversely in two 1 ayers (Figure 7). The visual and palpable exploration of liver area did not reveal the gallbladder but tense adhesions between duodenum and liver. No further manipulations took place.

The operation was uneventful, the patient extubated and transferred to the recovery room. While remaining there, the patient presented acute and severe respiratory deterioration. EKG and heart U/S weren't indicative of myocardial infarct or pulmonary embolism, while plain chest radiograph showed severe ARDS. The patient died two days later in ICU.

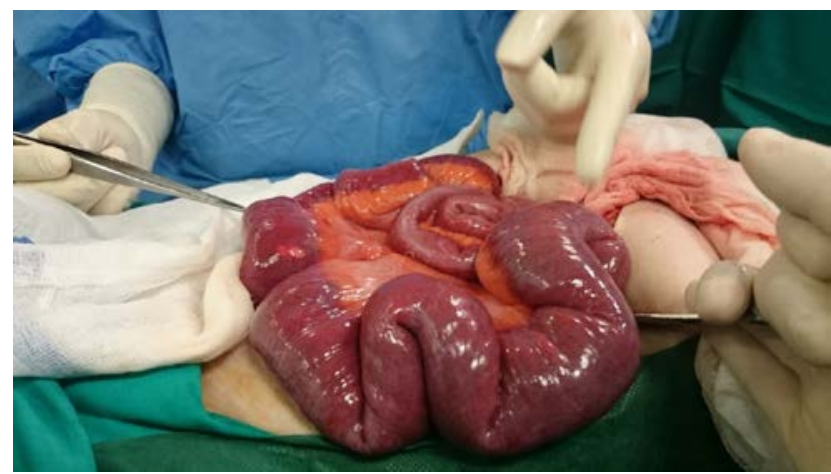

Figure 4. Laparotomy image of the gallstone impacted into the intestinum, with the dilated loops (on the left side of the picture, the pincher points exactly the impacted gallstone)

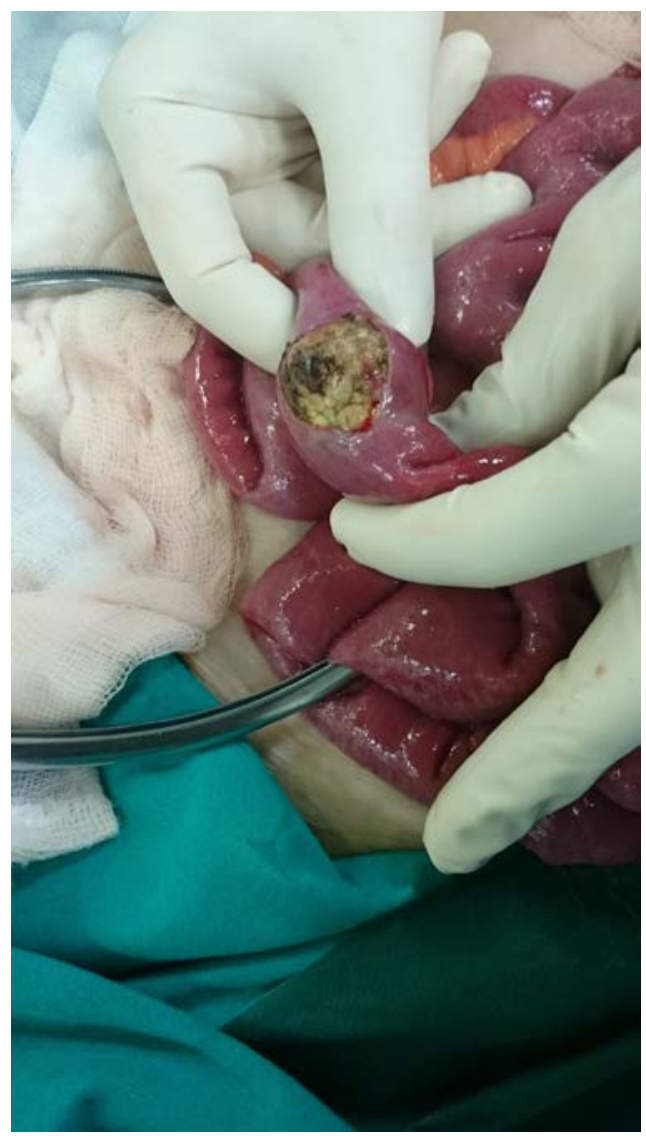

Figure 5. Laparotomy image of the enterolithotomy on the antimesenteric surface of the intestine 


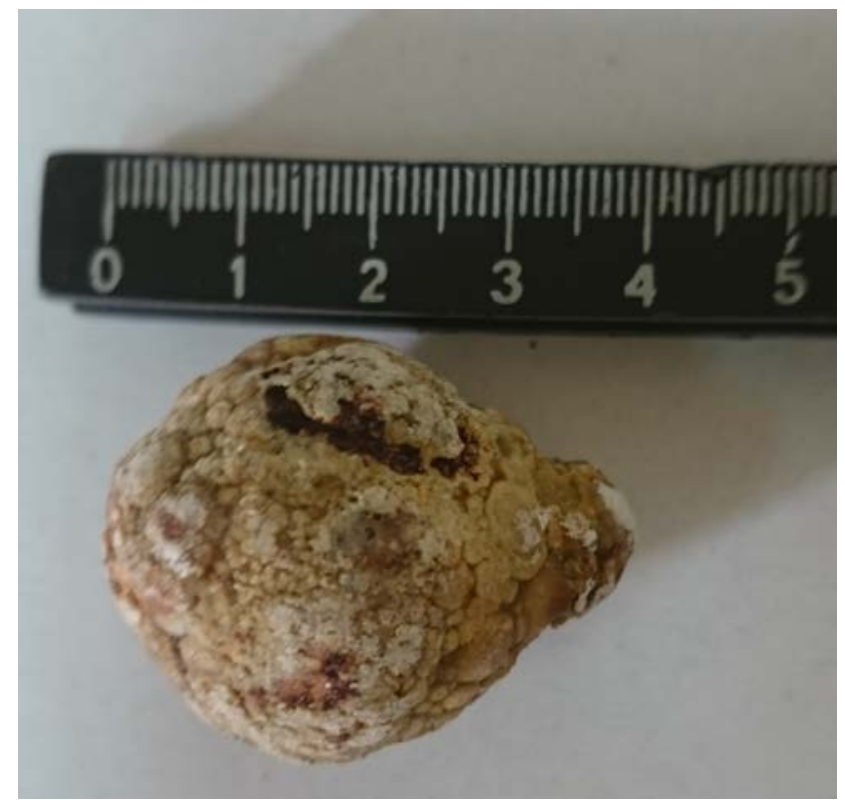

Figure 6. The gallstone.

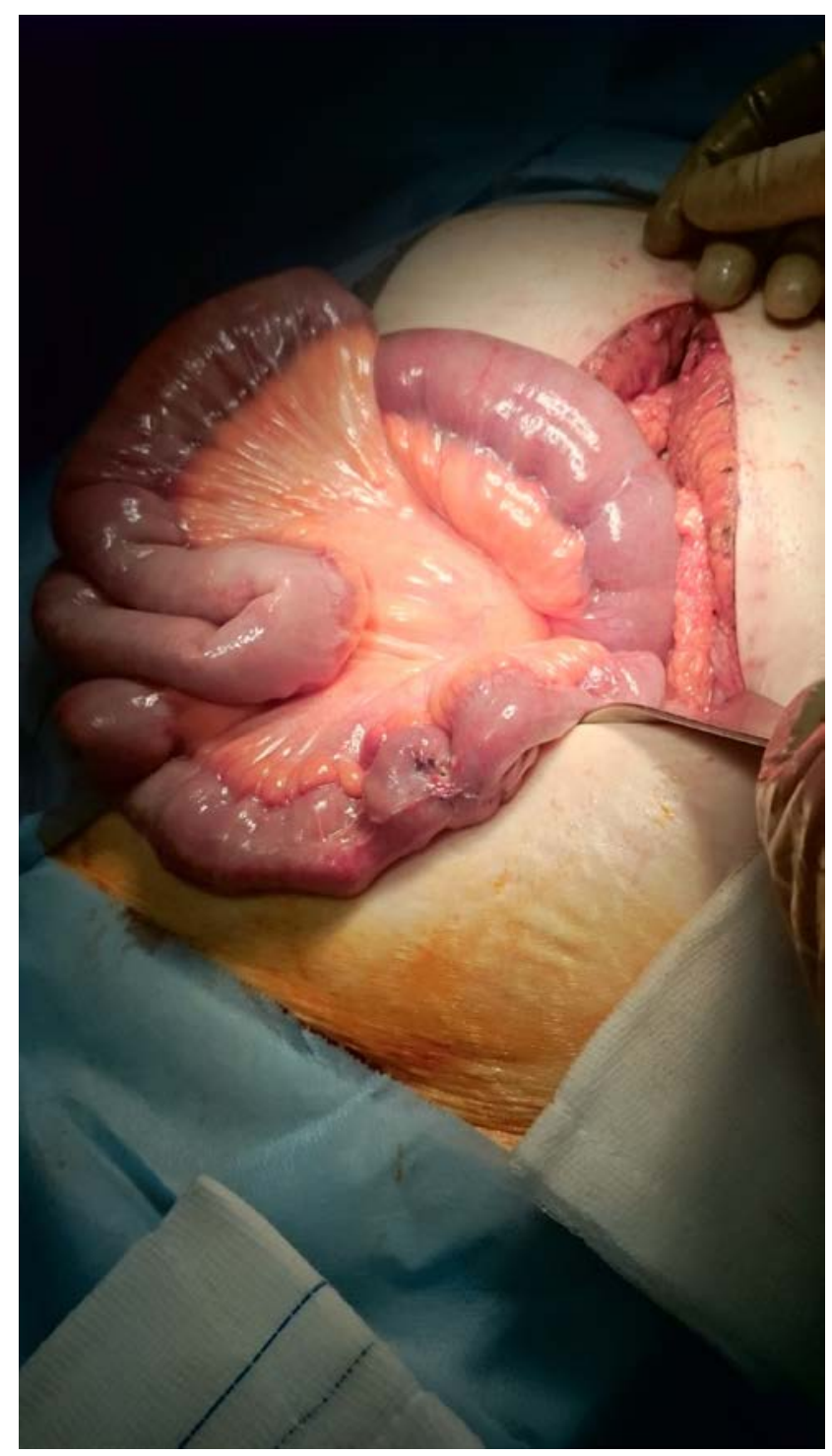

Figure 7. The repair of the enteromy
GI is a rare complication of cholelithiasis, accounting for $1 \%-4 \%$ of all cases of bowel obstruction $[3,4,5,6]$. Appears more often in elderly people, with $70 \%$ of patients being over 65 years old [7] and usually females, as the ratio is $3.5: 1[8,9]$.

Bowel obstruction occurs when gallstones measure $\geq 2$ $2.5 \mathrm{~cm}$ in diameter $[10,11,12]$. For gallstones smaller than $2.5 \mathrm{~cm}$ spontaneous passage through the bowel is possible, accounting for $1.3 \%$ of cases. Any part of the bowel can be affected, i.e. the ileum (60.5\%), jejunum (16.1\%), stomach (14.2\%), colon (4.1\%) and duodenum (3,5\%). Usually stone impaction occurs in the terminal ileum and the ileocecal valve because of the anatomically natural narrowing of the lumen $[13,14]$.

The diagnosis is difficult to be made based only on symptoms of nausea, vomiting, abdominal distension and pain, although many patients have a history of cholecystolithiasis. On plain abdominal radiography, classical signs of Rigler's triad (pneumobilia, dilated intestinal loops, aberrant gallstone) aid diagnosis [15].

A preoperative diagnosis of GI is feasible in only 50\%$60 \%$ of patients [16]. In $50 \%$ of cases definitive diagnosis is made at laparotomy [13]. With imaging studies (CT, MRI) the preoperative diagnosis is easier. Abdominal CT has an overall sensitivity, specificity and diagnostic accuracy of 93\%, 100\% and 99\%, respectively [17].

The interval between initial symptoms and admission ranges from 1 to 8 days, while the interval between admission and operation ranges from 3 to 4.5 days, due to delays in diagnosis and initial conservative treatment [18].

Besides conservative treatment and endoscopic efforts for stone extraction, there are various surgical options: 1 ) enterotomy with stone extraction only (more common), 2) enterotomy, stone extraction, cholecystectomy and fistula closure, 3) bowel resection only, and 4) bowel resection with fistula closure [3,9]. The surgical approach is based on the clinical condition of the patient $[5,9,19]$. Usually, the patients with GI are elderly with significant comorbidities and clinically unstable on admission, due to ileus. For such patients, enterolithotomy alone appears sufficient. Enterotomy is made by longitudinal incision placed on the antimesenteric side of the bowel, closely to the impaction site and issubsequently closed in two layers transversely, to avoid eventual narrowing of the intestinal lumen.

Treatment of fistulas remains controversial. Cholecystoduodenal fistula accounts for $60 \%$ to $86 \%$ of cases $[18,19,20]$. Intraoperative exploration hardly reveals fistulas. As a result, the operative time and intraoperative complications are increased, leading to higher prevalence of mortality. It ranges from $11.7 \%$ for theenterolithotomy procedure to $16.9 \%$ for the singlestage procedure (enterolithotomy, cholecystectomy, fistula closure) [3,13,19,21] to even $20 \%$ [22].

Spontaneous closure of the fistulas has been described in more than $50 \%$ of cases $[3,4,13,23]$. Prevalence of recurrent gallstone ileus is between 5\%-9\%4 and of biliary malignancy between 2\%-6\% [3].

In the literature, wound infections and dehiscence are the most common postoperative complications (25\%$50 \%$ ). Nonetheless, in some reports acute renal failure with pulmonal edema represents the most common postoperative complication [3,22].

\section{Discussion}


The patient in our case, although aged, had no significant personal medical record and was admitted to our hospital in good general condition. The intervals between symptoms and admission, as well as between admission and laparotomy were in the range of those mentioned in the literature. The operation was short and uneventful, with minimal intervention. Despite all these, the immediate recovery was complicated with acute respiratory deterioration, manifested initially with severe ARDS. Hemodynamic instability established progressively with renal failure, which ledto fatal outcome 48 hours later in the ICU.

\section{References}

[1] Ravikumar R, Williams JG. The operative management of gallstone ileus. Ann R Coll Surg Engl 2010; 92 (4): 279-281.

[2] Kasahara Y, Umemura H, Shiraha S, Kuyama T, Sakata K, Kubata H. Gallstone ileus. Review of 112 patients in the Japanese literature. Am J Surg 1980; 140 (3): 437-40.

[3] Dai XZ, Li GQ, Zhang F, Wang XH, Zang CY. Gallstone ileus: case report and literature review. World J Gastroenterol 2013; 19 (33): 5586-89.

[4] Michele D, et al. Usefulness of CT scan in the diagnosis and therapeutic approach of gallstone ileus: report of two surgically treated cases. BMC Surgery 2013; 13 (Suppl 2): S6.

[5] Doko M, Zovak M, Kopljiar M, Glavan E, Ljubicic N, Hochstadter $\mathrm{H}$. Comparison of surgical treatments of gallstone ileus: preliminary report. WJS 2003; 27 (4): 400-4.

[6] Tucker A, Gastrin I. A peculiar case of bowel obstruction. Int J Surg Case Report 2013; 4 (5): 473-6.

[7] Ayantunde AA, Agrawal A. Gallstone ileus: Diagnosis and management. WSJ 2007; 31 (6): 1292-97.

[8] Nakao A, Okamoto Y, Sunami M, Fujita T, Tsuji T.The oldest patient with gallstoneileus: report of a case and review of 176 cases in Japan. Kurume Med J. 2008; 55 (1-2): 29-33.

[9] Halabi WJ, Kang CY, Ketana N, Lafaro KJ, Nguyen VQ, Stamos MJ, Imagawa DK, Demirjian AN. Surgery for gallstone ileus: A
Nationwide comparison of trends and outcomes. Ann Surg 2013 Jan 4; Epub ahead of print.

[10] Syme RG. Management of gallstone ileus. Can J Surg 1989; 32 (1) 61-4.

[11] Ihara E, Ochiai T, Yamamoto K, Kabemura T, Harada N. A case of gallstone ileus with a spontaneous evacuation. Am J Gastroenterol 2002; 97 (5): 1259-60.

[12] Al-Obaid O. Gallstone ileus: a forgotten rare cause of intestinal obstruction. Saudi J Gastroenterol 2007; 13 (1): 39-42.

[13] Reisner RM, Cohen JR. Gallstone ileus: a review of 1001 reported cases. Am Surg 1994; 60 (6): 441-6.

[14] GuptaM, Goyal S, Singal R, Goyal R, Goyal SL, Mittal A. Gallstone ileus and jejunal perforation along with gangrenous bowel in a young patient: a case report. N Am J Med Sci 2010; 2 (9): 442-3.

[15] Rigler LJ, Borman CN, Noble JF. Gallstone obstruction: pathogenesis and roentgen manifestations. JAMA 1941; 117: 1753-9.

[16] Hayes N, Saha S. Recurrent gallstone ileus. Clinical Medicine and Research 2012; 10 (4): 236-9.

[17] Yu CY, Lin CC, Shyu RY,et al. Value of CT in the diagnosis and management of gallstone ileus. World J Gastroenterol 2005; 11 (14): 2142-7.

[18] Nuño-Guzmán CM, Arróniz-Jáuregui J, Moreno-Pérez PA, Chávez-Solís EA, Esparza-Arias N. Gallstoneileus: One-stage surgery in a patient with intermittent obstruction.World J Gastrointest Surg 2010; 2 (5): 172-6.

[19] Riaz N, Khan MR, Tayeb M.Gallstone ileus: retrospective review of a single centre's experience using two surgical procedures.Singapore Med J. 2008 Aug; 49 (8): 624-6.

[20] Freitag M, Elsner I, Gunl U, Albert W, Ludwig K. Clinical and imaging aspects of gallstone ileus. Experiences with 108 individual observations. Chirurg 1998; 69 (3): 265-9.

[21] de Alencastro MC, Cardoso KT, Mendes CA, Boteon YL, de Carvalho RB, Fraga GP.Acute intestinal obstruction due to gallstone ileus. Rev Col Bras Cir 2013; 40 (4): 275-80.

[22] Martín-Pérez J, Delgado-Plasencia L, Bravo-Gutiérrez A, BurilloPutze G, Martínez-Riera A, Alarcó-Hernández A, Medina-Arana y $\mathrm{V}$.[Gallstone ileus as a cause of acute abdomen. Importance of early diagnosis for surgical treatment.Cir Esp. 2013; 91 (8): 485-9.

[23] Clavien PA, Richon J, Burgan S, Rohner A. Gallstoneileus.Br J Surg 1990; 77 (7): 737-42. 